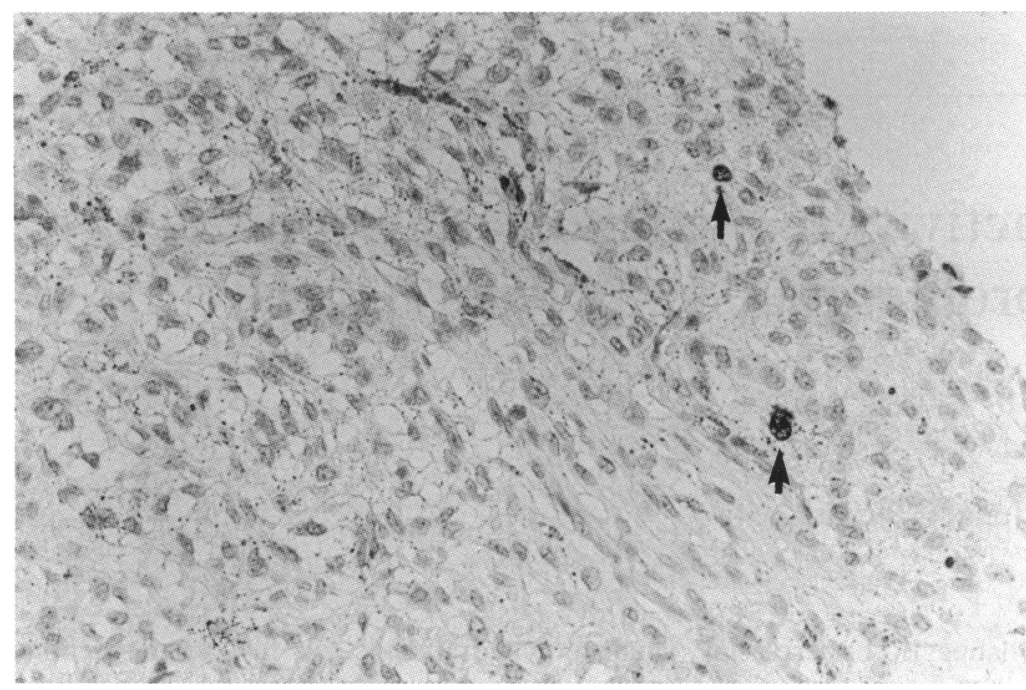

Figure 2 Photomicrograph of positive nuclear staining with Ki-67 $(\times 300)$.

strated by a proliferation associated antigen. Both the benign melanocytic hyperplasia and the melanoma were diploid, which is consistent with relatively benign tumours. Active proliferation may have led to malignant degeneration. The stimulus which leads to active proliferation of pre-existing anomalous melanocytes (that is, congenital uveal melanocytosis), is probably induced by a tumoral growth factor secreted by the primary tumour. ${ }^{1}$ The visual loss in our patient can be explained by the depigmentation of the retinal pigment epithelium and the photoreceptor atrophy.

The combination of Ota/Ito's naevus and BDUMH has been described ${ }^{3}$; however, multiple extraocular lentiginous pigmentations have so far not been recognised as part of this rare paraneoplastic syndrome.

Presented at the 32nd meeting of the European Ophthalmic Pathology Society, Sitges, 17-20 May, 1993.

1 Borruat FX, Othenon-Girard P, Uffer S, Othenin-Girard B Regli F, Hurlimann J. Natural history of diffuse uvea melanocytic proliferation. Case report. Ophthalmology 1992 ; 99: 1698-704.

2 Barr CC, Zimmerman LE, Curtin VT, Font RL. Bilateral diffuse melanocytic uveal tumors associated with systemic
malignant neoplasms. Arch Ophthalmol 1982; 100: 249-55.

3 Prause JU, Jensen OA, Eisgart F, Hansen U, Kieffer M. Bilateral diffuse malignant melanoma of the uvea associated with large cell carcinoma, giant cell type, of the lung. Case report of a newly described syndrome. Ophthalmologica 1984 189: 221-8.

4 Margo CE, Pavan PR, Gendelman D, Gragoudas E. Bilatera melanocytic uveal tumors associated with systemic malignancy: malignant melanomas or benign paraneoplastic syndrome? Retina 1987; 7: 137-41.

5 Bournier MN, McLean IW, Gamel JW. Immunohistochemica evaluation of uveal melanocytic tumors. Expression of HMB-45, S-100 protein, and neuron-specific enolase. Cancer 1991; 68: 809-14.

6 Steuhl KP, Rohrbach JM, Knorr M, Thiel HJ. Significance, specificity, and ultrastructural localization of HMB-45 antispecificity, and ultrastructural localization of HMB-45 anti208-15.

\title{
Adenoma of the pigmented ciliary epithelium
}

\author{
Ian G Rennie, Michael K Faulkner, M Andrew Parsons
}

\section{University of Sheffield, Department of Ophthalmology and Orthoptics \\ I G Rennie}

Department of Pathology M K Faulkner

\section{The Ophthalmic}

Sciences Unit

M A Parsons

Correspondence to: Mr I G Rennie, Department of Ophthalmology and Orthoptics, Royal

Hallamshire Hospital, Glossop Road, Sheffield S10 2JF.

Accepted for publication 13 December 1993
Tumours of the ciliary body pigment epithelium are extremely uncommon..$^{1-5}$ The correct diagnosis is rarely made clinically and, almost invariably, the eye is enucleated or the lesion resected because a malignant melanoma of the ciliary body is suspected. We describe a locally invasive tumour arising from the pigment epithelium of the ciliary body which was removed by surgical resection.

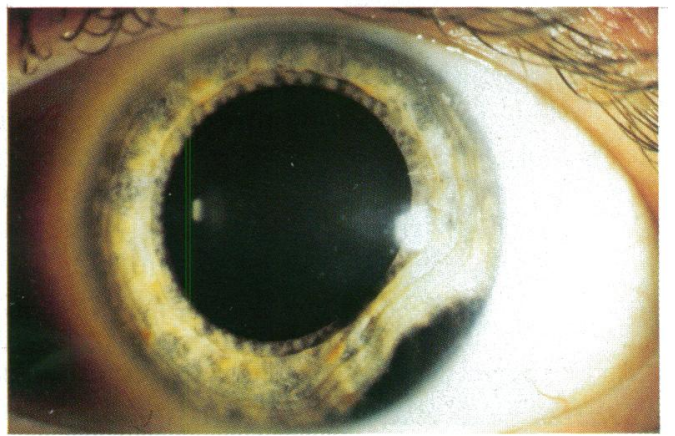

Figure 1 Clinical appearance of the tumour. Note the local distortion of the iris and the multinodular surface of the lesion.

\section{Case report}

A 40-year-old man was referred to this unit with a pigmented tumour arising from the ciliary body of his left eye. The patient had noted a black mark on the periphery of his left iris 1 month before this which had prompted his referral. On examination his uncorrected visual acuities were $6 / 5$ in both eyes. A deeply pigmented multinodular mass was noted in the inferotemporal iridocorneal angle of the left eye (Fig 1). The lesion, which occupied approximately two clock hours, had displaced the adjacent iris anteriorly causing a focal shallowing of the anterior chamber. Fundurscopy revealed a displacement of the ciliary processes overlying the lesion. Transillumination through a dilated pupil revealed an area of shadowing corresponding to this area. The intraocular pressures were $23 \mathrm{~mm} \mathrm{Hg}$ in both eyes. The remainder of the ocular examination was unremarkable. A full physical examination, including liver enzyme profile, chest $x$ ray, and abdominal ultrasound was normal. Clinically, the lesion was thought to be a malignant melanoma arising from the ciliary body with iridocorneal angle invasion. The tumour was 


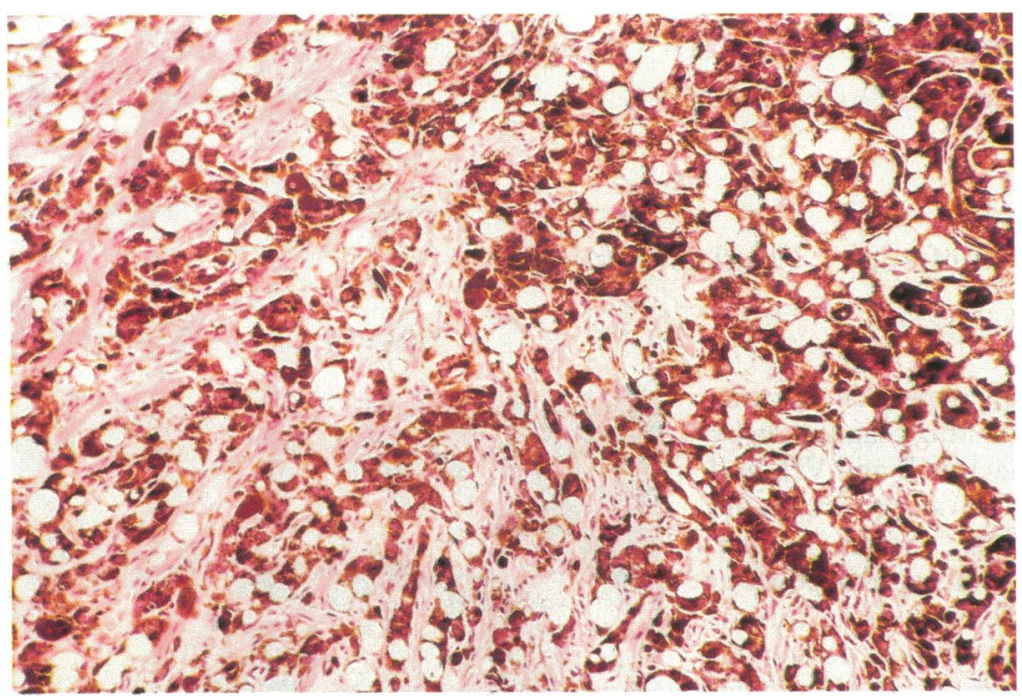

Figure 2 The tumour is composed of deeply pigmented cells with small round nuclei. Many tumour cells contain large vacuoles. (Haematoxylin and eosin, magnification $\times 190$.)

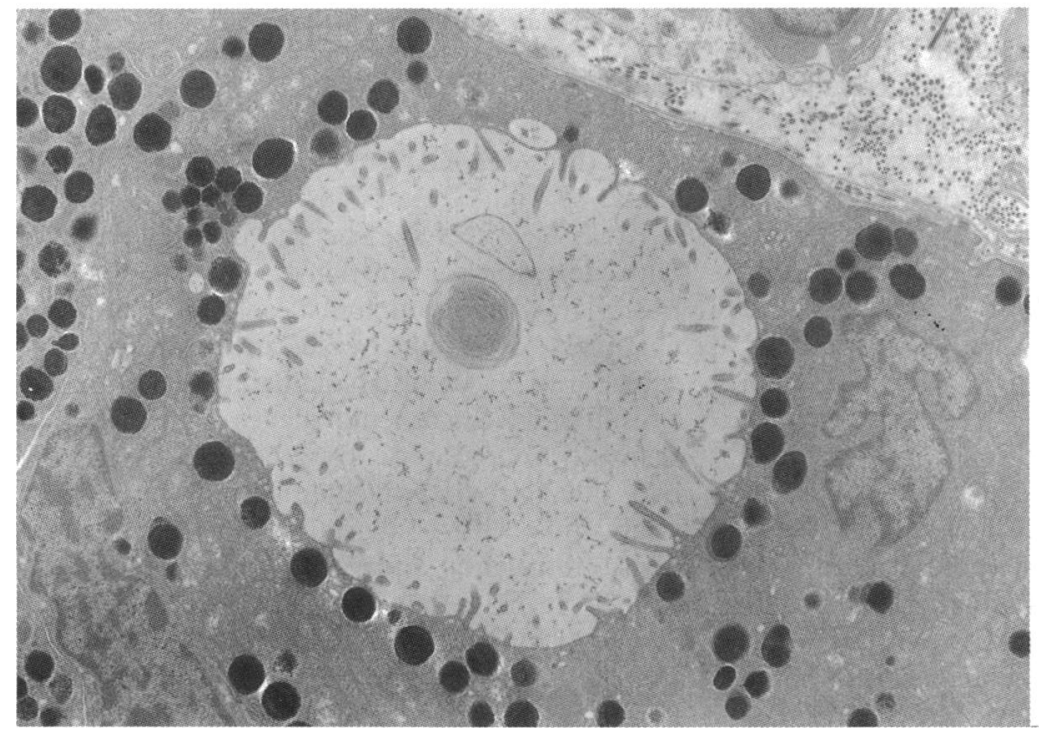

Figure 3 An electron micrograph showing a tumour cell with a prominent intracellular vacuole lined with microvilli. (Original magnification $\times 2800$.)

locally excised by means of an iridocyclectomy. Postoperative progress was satisfactory and when the patient was last examined a year following the surgery the uncorrected visual acuity in the left eye was $6 / 6$. There was no evidence of any local recurrence of the lesion.

\section{Pathological findings}

\section{LIGHT MICROSCOPY}

The specimen consisted of a deeply pigmented tumour which had almost completely replaced the normal ciliary body and was composed of large cells with relatively small round nuclei. Many cells contained prominent clear vacuoles. There was extensive infiltration of the underlying ciliary muscle by the tumour cells (Fig 2). Involvement of the adjacent sclera and trabecular meshwork was also present. Only occasional mitotic figures were noted.

\section{ELECTRON MICROSCOPY}

Ultrastructural examination revealed the tumour to be composed of cells containing numerous round mature melanosomes, moderate numbers of mitochondria, and scanty rough endoplasmic reticulum (Fig 3). Many cells contained large vacuoles which appeared lined with microvilli. A well developed basement membrane was present along the borders of occasional cells, while in other areas adjacent cells were joined by tight cellular junctions.

\section{FLOW CYTOMETRY}

Fresh tumour samples were taken immediately after removal of the tumour and analysed by flow cytometry for ploidy using a previously published technique. ${ }^{6}$ The tumour was found to contain both diploid (31\%) and aneuploid (69\%) cells.

\section{Comment}

Both adenomas and adenocarcinomas of the pigmented ciliary epithelium (PCE) have been described, although the distinction between them would seem somewhat arbitrary. The presence of local tissue invasion or cellular pleomorphism has been used by some authors as the criterion for malignancy, ${ }^{157}$ while others have described similar lesions as adenomas despite infiltration of local structures. ${ }^{2-4}$ To date, there has not been a reported case of a tumour of the pigmented ciliary epithelium producing metastases. Although the tumour reported here had infiltrated local structures and, interestingly, exhibited a high degree of aneuploidy, we believe this tumour, in the absence of a proved metastatic potential, should be classified as an adenoma of the PCE.

This tumour, in keeping with most other reported cases, was initially diagnosed as a choroidal melanoma with anterior chamber extension. Although the differentiation is difficult, with hindsight there appear to be a few clinical features which should alert the physician to the correct diagnosis. Firstly, extensive invasion of the iris root was disproportionate to the relatively small size of the ciliary body tumour. Furthermore, the anterior chamber extension of the tumour had a multinodular or lobulated surface which closely resembles the clinical appearance of other reported cases. ${ }^{12}$ This case emphasises the usefulness of local surgical resection as a method of treating small ciliary body tumours.

We thank Mr J Lawry for performing the flow cytometry, Professor W R Lee for his expert advice, and Mr B Noble for kindly referring this patient.

1 Streeten BW, McGraw JL. Tumor of the ciliary pigment epithelium. Am f Ophthalmol 1972; 74: 420-9.

2 Wilensky JT, Holland MG. A pigmented tumor of the ciliary body. Arch Ophthalmol 1974; 92: 219-20.

3 Naumann G, Volcker HE, Lerche W. Denom des pigmentierten ciliarepithels: klinische, histochemische und elektronmikroskopische befunde und literatur-ubersicht. Graefes mikroskopische befunde und literatur-ubersic

4 Chang M, Shields JA, Wachtel DL. Adenoma of the pigment epithelium of the ciliary body stimulating a malignant epithelium of the ciliary body stimulatin
melanoma. Am $\mathcal{f}$ Ophthalmol $1979 ; 88: 40-4$.

5 Papale JJ, Akiwama K, Hirose T, Tsubota K, Hanaoka K, Albert DM. Adenocarcinoma of the ciliary body pigment epithelium in a child. Arch Ophthalmol 1984; 102: 100-3.

6 Rennie IG, Rees RC, Parsons MA, Lawry J, Cottam D. Estimation of DNA content in uveal melanomas by flow cytometry. Eye 1989; 3:611-7.

7 Dryja TP, Albert DM, Horns D. Adenocarcinoma arising from the epithelium of the ciliary body. Ophthalmology 1981; 88: $1290-2$. 